\title{
Unravelling the Potential of Salivary Volatile Metabolites in Oral Diseases. A Review
}

\author{
Jorge A. M. Pereira ${ }^{1, *(\mathbb{D}}$, Priscilla Porto-Figueira ${ }^{1}$, Ravindra Taware ${ }^{2}$, Pritam Sukul ${ }^{3}{ }^{(\mathbb{D}}$, \\ Srikanth Rapole 2 (D) and José S. Câmara $1,4, * \mathbb{D}$ \\ 1 CQM-Centro de Química da Madeira, Universidade da Madeira, Campus da Penteada, \\ 9020-105 Funchal, Portugal; priscillaportofigueira@gmail.com \\ 2 Proteomics Lab, National Centre for Cell Science (NCCS), Ganeshkhind Road, SPPU Campus, \\ Pune 411007, India; ravindra.taware@nccs.res.in (R.T.); rsrikanth@nccs.res.in (S.R.) \\ 3 Department of Anaesthesiology and Intensive Care Medicine, Rostock Medical Breath Research Analytics \\ and Technologies (ROMBAT), Rostock University Medical Centre, 18057 Rostock, Germany; \\ pritam.sukul@uni-rostock.de \\ 4 Faculdade de Ciências Exatas e da Engenharia, Universidade da Madeira, Campus da Penteada, \\ 9020-105 Funchal, Portugal \\ * Correspondence: jorge.pereira@staff.uma.pt (J.A.M.P.); jsc@staff.uma.pt (J.S.C.); \\ Tel.: +351-291-705-119 (J.A.M.P.); +351-291-705-112 (J.S.C.)
}

Academic Editors: Luigi Perbellini and Lorenzo Monasta Received: 9 June 2020; Accepted: 6 July 2020; Published: 7 July 2020

\begin{abstract}
Fostered by the advances in the instrumental and analytical fields, in recent years the analysis of volatile organic compounds (VOCs) has emerged as a new frontier in medical diagnostics. VOCs analysis is a non-invasive, rapid and inexpensive strategy with promising potential in clinical diagnostic procedures. Since cellular metabolism is altered by diseases, the resulting metabolic effects on VOCs may serve as biomarkers for any given pathophysiologic condition. Human VOCs are released from biomatrices such as saliva, urine, skin emanations and exhaled breath and are derived from many metabolic pathways. In this review, the potential of VOCs present in saliva will be explored as a monitoring tool for several oral diseases, including gingivitis and periodontal disease, dental caries, and oral cancer. Moreover, the analytical state-of-the-art for salivary volatomics, e.g., the most common extraction techniques along with the current challenges and future perspectives will be addressed unequivocally.
\end{abstract}

Keywords: saliva; volatile organic compounds (VOCs); oral diseases (ODs); biomarkers; analytical platforms

\section{Introduction}

Worldwide, oral diseases (ODs) are highly prevalent affecting over 3.5 billion people, particularly in low- and middle-income countries (LMICs) [1]. ODs compromise very seriously the overall health and wellbeing, causing a myriad of conditions to the patient, as pain, sepsis and reduced life quality. Additional side effects, as loss of school days, family disruption, decreased work productivity or dental treatment costs, have a significant impact in the healthcare systems and society. According to Peres et al. [1], dental caries (tooth decay), periodontal disease, tooth loss, and cancers of the lips and oral cavity are among the most prevalent ODs. Although different procedures have been described for early detection in order to cope with these diseases, the diagnostic efficiencies greatly depend on the clinical conditions of the patients [2-4]. Nevertheless, a non-invasive method using saliva for ODs diagnostics is a highly attractive strategy. Saliva is often described as the "mirror of the body" $[5,6]$ and so different omics approaches such us proteomics, metabolomics and more recently, volatomics are being employed to explore the potential of this biofluid towards the non-invasive diagnosis of ODs [5]. 


\section{Physiology of Saliva}

\section{Saliva Composition and Production}

In its broader sense, saliva composition includes the fluids produced by the different salivary glands and the gingival-crevicular secretions, along with cellular components, oral microbiota as well as food debris [7]. Saliva is a colourless liquid, slightly acidic, hypotonic and a mucoserous exocrine biological medium mainly composed of water $(98 \%)$ with a production of approximately $0.5-1.5 \mathrm{~L}$ per day $[5,6,8]$. It is also possible to find different organic compounds including hormones, peptides, mucus, antibacterial compounds, enzymes, proteins, urea, uric acid, lactate and creatinine $[2,4,8,9]$. Ions such as $\mathrm{Na}^{+}, \mathrm{K}^{+}, \mathrm{Ca}^{2+}, \mathrm{Cl}^{-}$and $\mathrm{HCO}^{3-}$, are also present in saliva $[5,9]$. The overall composition of saliva is affected by internal (related to the type of secretory glands and their stimulation) and external (personal habits including diet and lifestyle) factors $[5,9,10]$. A deeper understanding of the interplay of these factors on saliva production and composition can be found elsewhere [11,12].

The autonomic nervous system plays a key role in the production of saliva. This control is exerted by various nerves that regulate the viscosity, flow rate, volume and concentration of various constituents of saliva. The sublingual and minor mucus glands are regulated by stimulation of sympathetic nerves whereas the parotid and submandibular glands are stimulated by the parasympathetic innervation $[4,5,8,13]$. Saliva is mostly produced by three pairs of major salivary glands: (i) parotid (which contribute for $\sim 23 \%$ of a total saliva production), (ii) submandibular (which contribute for $\sim 65 \%$ of a total saliva production) and (iii) sublingual (which contribute for a $\sim 4 \%$ of a total saliva production (Figure 1) $[4,5,8,9]$. Additionally, numerous minor salivary glands (around 300-1000 units of von Ebner's, mucous gland, labial and palatine glands, among other) distributed throughout the oral mucosa contribute with around $\sim 8 \%$ of total saliva production $[4,5,8,13]$. Each type of salivary gland produces a specific secretion $[8,10]$. The parotid produces a serous fluid, the submandibular a sero-mucous, the sublingual secretes only mucous saliva and the minor glands produce viscous secretions $[8,10]$. The initial or primary saliva is an isotonic fluid produced by the acini, a cluster of cells (acinus) with a berry-type structure that are present in the salivary glands. These acini drain into the salivary ducts with small 'striated' ducts opening into wider intercalated and excretory ducts $[10,14]$. The acini are surrounded by blood capillaries that enable the exchange of substances from the circulation into the salivary glands [10]. This transport is done through three distinct mechanisms, namely selective transport using passive diffusion, ultrafiltration through pores or active (energy-dependent) transport against concentration gradients leading to the enrichment of the saliva composition $[8,10,14,15]$ (Figure 1). During the passive diffusion, several compounds cross the cell membranes of capillaries and acini. Lipid-soluble compounds (e.g.,: unconjugated steroids) are close to unbound plasma concentrations, while hydrophilic compounds (e.g.,: conjugated steroids) reach only $1 \%$ of unbound plasma concentrations $[3,8,14]$. In turn, small polar molecules (having molecular weight below $1.9 \mathrm{kDa}$, as ions and some hormones) can be transported to saliva by ultrafiltration [8,14]. This transport is done through narrow junctions in the apical pole of the acini. Finally, for some electrolytes and larger molecules like peptides, the passage from capillaries to saliva will be dependent on an active transport mechanism $[8,10,14]$. Beyond these mechanisms of transport from the capillaries, elements such as bacteria, epithelial cells, erythrocytes, leukocytes, food debris or other contaminants may be also present in the saliva, causing significant variations to the final saliva composition $[3,8]$. This fact is particularly relevant in the context of the applicability of saliva as a diagnostic tool for different diseases. The connection between local (salivary glands) and systemic (blood) circulation sources provides a good option for looking into disease biomarkers or studying a physiological state. Moreover, saliva can be collected non-invasively, more affordable, accessible and painless way than blood, for instance $[8,13]$. 


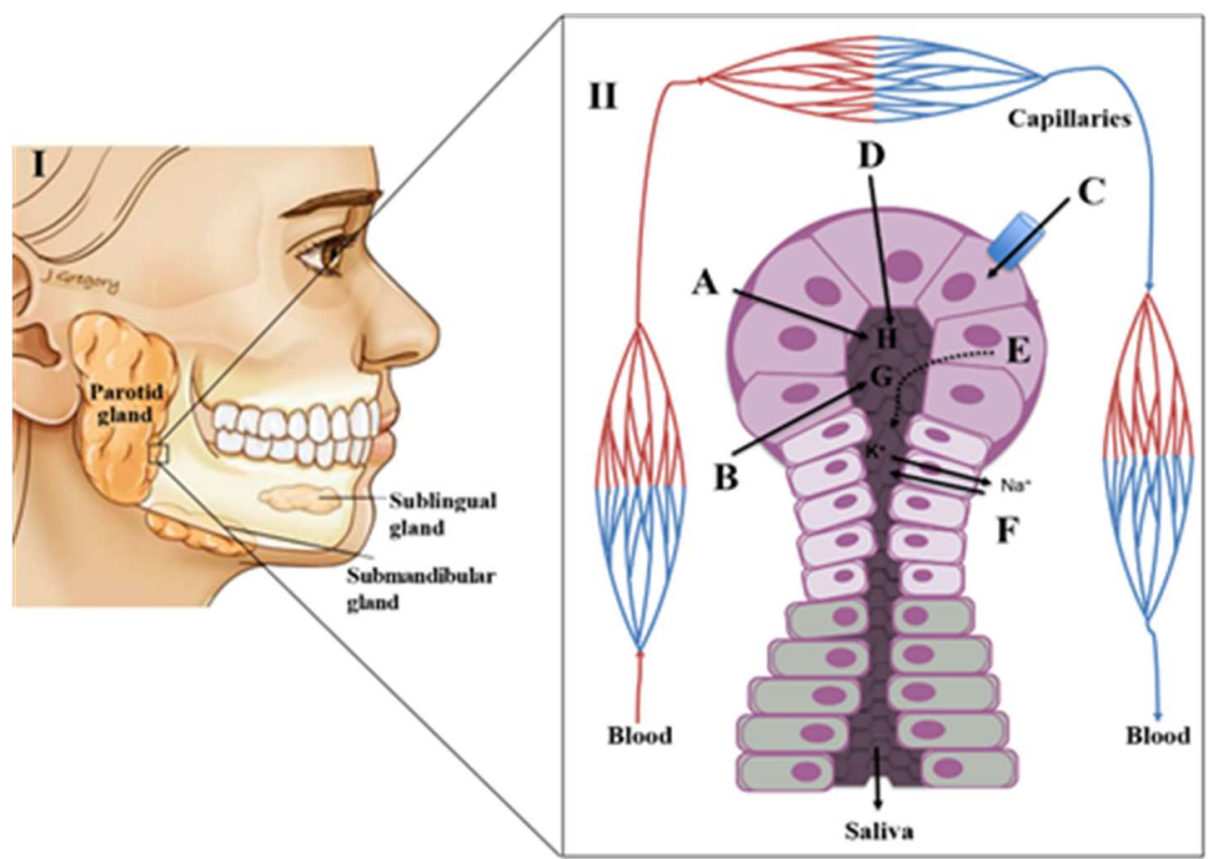

Figure 1. (I)-The major salivary glands; (II)-Acini structure and the different mechanisms of transport of plasma compounds into a salivary gland. A-Entry of components by simple filtration; B-Entry of liposoluble compounds by passive diffusion $\mathrm{C}$-active transport; $\mathrm{D}$-Active pumping of $\mathrm{Na}+$ ions and concomitant entry of $\mathrm{H}_{2} \mathrm{O}$; E-component produced/secreted by the salivary glands; F-Pumping of $\mathrm{Na}+$ ions into the blood producing hypotonic fluid; G-Liposoluble compounds; $\mathrm{H}-\mathrm{H}_{2} \mathrm{O}$, electrolytes (adapted from [16]).

\section{Putative Salivary Biomarkers for Oral Diseases}

As mentioned, ODs are a serious problem worldwide, affecting mostly the poor and marginalized groups in society with particularly higher incidence rate observed in the LMICs [1]. Strikingly, the most prevalent ODs tooth decay (caused by dental caries) and periodontal disease (gum inflammation) could be easily preventable with better oral care and access to medical services. It is therefore remarkable how such problems continue to be neglected. Cancers of the lips and oral cavity are also very prevalent, ranking in the top 15 of most common cancers in the world in 2018 [17]. Several other conditions can affect the oral cavity and its soft and hard tissues, but fortunately they have a lower global impact. The risk factors for the development of ODs are well-known, being the most relevant the abuse of sugar, alcohol and tobacco. In turn, these risk factors are also the main cause of other clinical conditions, as diabesity (diabetes and obesity co-occurrence), caries (excessive sugar consumption) and different forms of cancer (alcohol and tobacco abuse) [1]. Therefore, it is not surprising that great deal of efforts were made to identify the salivary biomarkers for ODs.

Despite its apparent simplicity, saliva contains a large repertoire of proteins $(>3600)$ and peptides $(>12,000)$, being a great part of them ( $~ 50 \%$ of proteins and $80 \%$ of peptides) also found in plasma $[18,19]$. This feature is most probably caused by the exchange of molecules with the crevicular fluid at the periodontal pocket of sulcus through passive diffusion, pinocytosis and the fusion pores of acinar cells as represented in Figure $1[20,21]$. Consequently, saliva can be a very informative biofluid regarding the hormonal, immunological, nutritional and physiological status of an individual [7]. Most of the proteins found in saliva are low molecular weight proline-rich proteins transcribed from chromosome 12 [22]. The salivary proteome is largely modified by various post-translational modifications including glycosylation, phosphorylation, acetylation, ubiquitination, and methylation among others which constitute a genome-independent and specific "biosignature" [23]. Such signature will be obviously modulated by specific patterns of proteome alterations associated with ODs, constituting an important diagnostic tool to unveil putative biomarkers for different conditions. At this point should be clarified 
that many of the studies included in this section points to putative biomarkers that still require further validation before they can be reliably used in the clinical environment.

\subsection{Gingivitis and Periodontal Disease}

Gingivitis constitutes the initial stage of periodontal disease characterized by the inflammation of gums or gingiva. It is caused by the bacterial plaques build up on teeth and consequent inflammation of the surrounding tissues [24]. If not treated properly, gingivitis will progress to periodontal disease-causing tissue and bone degradation and eventual tooth loss. A non-targeted proteomic analysis of saliva by two-dimensional gel electrophoresis (2DE) and matrix-assisted laser desorption/ionization time-of-flight mass spectrometry (MALDI-TOF MS) identified the upregulation of immunoglobulin and keratins in gingivitis patients $(n=10)$ as compared to controls $(n=10)$ [25]. Another non-targeted study of saliva, found several proteins (among mucins, albumins, lactoferrins, histatins and amylases) altered in periodontitis [26-29]. The label free quantitative proteomic analysis of a periodontitis cohort by Bostanci et al. [30] revealed that lactoferrin, lacritin, sCD14, Mucin 5B and Mucin7 levels were reduced as compared to controls. This result suggests that the lower disease resistance offered by periodontitis patients is due to the reduced antimicrobial properties exhibited by their saliva. The matrix metalloproteinases (MMPs) are the proteases involved in the extracellular matrix remodelling and linked to periodontal inflammation and collagen degradation [31]. Particularly, MMP8 is considered as important biomarker for periodontitis. Furthermore, recent proteomic investigation also confirmed that MMP8 along with other cytokines (interleukin-1b-IL-1b, RANK/RANKL/OPG) were overexpressed in periodontitis [32]. In fact, Gursoy et al. [33] proposed a cumulative risk score using the salivary concentrations of Porphyromonas gingivalis, IL-1 $\beta$, and MM8 as a novel and non-invasive model for the risk assessment of advanced periodontitis. The level of several other salivary cytokines, IL-6, IL-8, IL-17A, and tumour necrosis factor $\alpha$ (TNF- $\alpha$ ) have been shown to be affected by periodontitis progress [34]. The identification of so many inflammatory markers in different studies involving periodontitis seems obvious given the progression of the gum inflammation from an initial gingivitis stage to periodontitis. In this case, however further studies are necessary to identify which markers are specific to the gum inflammation.

Aimetti et al. [35] carried out metabolomic analysis of saliva samples applying proton nuclear magnetic resonance ( $\left.{ }^{1} \mathrm{H}-\mathrm{NMR}\right)$ to a cohort of 43 individuals ( 21 chronic periodontitis patients and 22 controls). They found that high concentrations of short chain fatty acids such as acetate, propionate, $n$-butyrate along with succinate, valine, phenylalanine and trimethylamine are associated with chronic periodontitis. In contrast, the authors also detected low pyruvate and $n$-acetyl groups concentrations in same study cohort. Several other studies using the same approach and clinical cohorts of periodontitis of various strengths also identified augmented levels of amino acids, alcohols, short chain fatty acids and sugars in the disease group [36-39]. Apart from ${ }^{1} \mathrm{H}-\mathrm{NMR}$, gas chromatography-mass spectrometry (GC-MS) and liquid chromatography-mass spectrometry (LC-MS) were also employed to detect metabolic signatures associated with the periodontitis. Liebsch et al. performed ultra-high pressure liquid chromatography-tandem mass spectrometry (UHPLC-MS/MS) metabolomic analysis of a cohort of 909 subjects and identified the bacterial metabolite phenylacetate as a potential biomarker for periodontitis across all age groups [40]. Huang et al. carried out targeted (LC-MS) and untargeted (GC-MS) lipid profiling of saliva samples in a study involving 50 periodontitis patients and 50 healthy controls. The authors observed increased levels of some prostaglandins, namely PGE2, PGD2, PGF2 $\alpha$, and thromboxane 2, and decreased levels of others, such as PGI2, in periodontitis patients. Moreover, they also reported elevated levels of 5-HETE (arachidonic acid metabolite) and decreased levels of 13-HODE and 9-HODE (linoleic acid metabolites) in periodontitis patients [41]. In another study, the salivary macrophage inflammatory protein- $1 \alpha$, MM8, IL-1 $\beta$, IL-6, prostaglandin E2 and TNF- $\alpha$ levels were reported to correlate with gingivitis and periodontitis development [42]. Finally, aggressive periodontitis has been associated to an exacerbated production of adrenomedullin and nitric oxide (NO) in saliva [43]. At a different level, the detection of $P$. gingivalis using saliva kits may 
constitute another important tool for ODs study by providing an easy and time-efficient chair-side tool for the detection of $P$. gingivalis [44].

\subsection{Dental Caries}

Tooth decay, also known as dental caries, is one of the major ODs observed across all age groups worldwide. This multifactorial disease is triggered by the excessive consumption of fermentable carbohydrates (sugars, as glucose, fructose, sucrose and maltose), poor oral hygiene and inadequate fluoride exposure [45]. This combination eventually results in the formation and progression of a microbial biofilm producing acids which cause the demineralization of dental tissues and finally dental cavities [45]. Given that the prevalence of dental caries is positively correlated with the microbial load of Streptococcus mutans and Lactobacillus in the saliva [46], these two bacteria should be involved in the cascade leading to tooth decay. Porphyromonas gingivalis is another bacterium with a relevant role in ODs as it was implicated in the biofilm formation of bacterial plaque. Furthermore, it also plays an important role in the progression of periodontal disease as well as in the onset of different systemic pathologies, including rheumatoid arthritis, cardiovascular pathologies, and neurodegenerative pathologies (reviewed in [47]).

Vitorino et al. [45] used a gel-based proteomic approach to study dental caries formation and identified reduced levels of acidic proline rich phosphoproteins associated with the higher risk of caries [48]. However, the other proteins involved in this study, such as agglutinins, amylase, lactoferrin, lysozyme and some antibacterial peptides, were found to be inconsistent with a diagnostic potential. In turn, Fidalgo et al. [46] carried out ${ }^{1} \mathrm{H}-\mathrm{NMR}$ studies of saliva sample to identify the metabolomic fingerprint associated with the dental caries in children [49]. In a study group of 33 subjects (dental caries $=15$, control $=18$ ), the authors identified lactate, acetate and n-butyrate significantly increased in dental caries subjects as compared to control group.

\subsection{Oral Cancer}

Oral cancer is the sixth most frequent malignant disease across the globe and oral squamous cell carcinoma (OSCC) is the most often reported subtype. The onset of oral cancer is often asymptomatic, but overall seems to be outcome of progressive premalignant conditions such as leukoplakia and oral lichen planus [50,51]. Metabolic reprogramming in oral cancer is not yet well understood and therefore, investigation of metabolic alterations is crucial for detecting novel diagnostic biomarkers and understand the disease progression. In a couple of studies saliva was used to unveil the metabolomic signature of oral cancer. Sugimoto et al. [52] carried out a salivary metabolomic analysis by capillary electrophoresis time-of-flight mass spectrometry (CE-TOF-MS) using a cohort of 156 individuals comprising of 69 patients with oral cancer and 87 controls. Overall, 57 metabolites were detected and out of these, 28 were found to be differentially expressed in oral cancer as compared to controls. Higher levels of salivary polyamines, piperidines and taurine were detected in oral cancer group and considered as promising screening biomarkers. In another study, Ishikawa et al. [50] reported that s-adenosylmethinine and pipecolate were upregulated in the saliva of oral cancer patients as compared to the control samples and possess a good diagnostic potential for the early detection of the disease [53]. In another study, the same authors proposed that the salivary metabolites indole-3-acetate and ethanolamine phosphate have the potential to discriminate OSCC from oral leukoplakia (OLP) [54]. Wei et al. [55] performed a salivary metabolomic study in three groups comprising oral cancer, oral leukoplakia and controls by UPLC coupled with Quadrupole TOF-MS. The study revealed that the metabolic set composed by valine, phenylalanine and lactic acid exhibits a moderate specificity and sensitivity to discriminate oral cancer from oral leukoplakia and controls [55]. Using the same approach, Wang et al. [56] performed a salivary metabolomic analysis using a cohort of 60 subjects (30 oral cancer patients and 30 controls subjects). The authors reported a pool of five salivary metabolites (propionylcholine, N-acetyl-L-phenylalanine, sphinganine, phytosphingosine, and S-carboxymethyl-L-cysteine) exhibiting good sensitivity, specificity and accuracy to discriminate 
oral cancer patients from controls. Furthermore, Lohavanichbutr et al. [57] applied ${ }^{1} \mathrm{H}-\mathrm{NMR}$ and LC-MS/MS to unveil putative salivary metabolic signatures for oral cancer and observed that glycine and proline were significantly altered in the malignant group when compared to the controls.

The earliest salivary proteomics analysis of OSCC pointed out the role of higher levels of several cytokines (IL-6, IL-8, IL-1 and TNF- $\alpha$ ) in the proinflammatory and proangiogenic functions [58]. Related with this, more recently Aziz et al. reported augmented levels of IL-4, IL-10, IL-13 and IL-1RA in the saliva of patients with OSCC [59]. In another study, immunoglobulins were detected at higher levels in OSCC patients as compared to controls and found to be involved in angiogenesis [60]. A similar observation was reported for several cell surface receptor glycoproteins, namely CD44, CD59 and CEA, which were found overexpressed in patients with OSCC [61]. Different zinc finger proteins were also found augmented in OSCC patients, namely ZNF510 [62] or Cyfra 21-1 and CK 19 [61-63]. Hu et al. [59] performed a global proteomic analysis of salivary samples (OSCC $=64$, control $=64$ ) and proposed a panel of five proteins (M2BP, MRP14, CD59, catalase and profilin) which exhibit with high sensitivity $(90 \%)$ and specificity $(83 \%)$ to discriminate OSCC patients from controls. In a larger study, Yu et al. carried out proteomic analysis of a cohort comprising 131 OSCC patients, 103 low risk OPMDs (oral potentially malignant disorders) patients, 130 high risk OPMDs patients and 96 controls. The authors proposed four proteins-MMP1, KNG1, ANXA2 and HSPA5 that were not only able to discriminate the OSCC from controls, but also predict OPMDs progression into OSCC [64]. In a very recent study of OSCC salivary proteome, Sivdasan et al. reported CD44, S100A7 and S100P as novel potential biomarkers for the early detection of OSCC [65]. DNA methylation and conformational alterations on histones are potential molecular signatures for different cancers, including those affecting the salivary glands [66]. Under this context, Li et al. observed that the long non-coding RNA (lncRNA) RBM5-AS1, which promotes the proliferation, migration, and invasion of OSCC cells in vitro, was highly expressed in OSCC tumour tissues and cancer cell lines [67]. Furthermore, Park et al., reported that OSCC patients have lower levels of salivary miR-125a and miR-200a, strongly suggesting that specific salivary miRNAs can be used in oral cancer detection [68].

\subsection{Oral Potentially Malignant Disorders (OPMD)}

OPMDs are clinical manifestations that aggregate conditions as the oral lichen planus and oral leukoplakia (OLP), which possess risk of malignant transformation. Several prospective studies have predicted a 1\% progression rate of OPMD into oral cancer [69,70]. Yang et al. [71] carried out 2DE and MALDI-TOF MS analysis of an OLP study cohort comprising 20 cases (patients $=10$, control $=10)$ and reported an urinary up-regulated prokallikrein and reduced palate, lung and nasal epithelium carcinoma-associated protein (PLUNC) as novel biomarkers for oral lichen planus. In another study, Souza et al. [72] discovered a positive correlation of S1008, S1009 and haptoglobin with the inflammatory cytokines and oral lichen planus pathology. Furthermore, Camisasca et al. [73] performed a 2DE-MALDI-TOF analysis of a leukoplakia cohort consisting of 15 patients and 10 controls and identified keratin 10 as an important candidate protein biomarker for the disease pathology.

\subsection{Burning Mouth Syndrome}

Burning mouth syndrome is characterized by a chronic intraoral inflammation without any visible lesions in oral cavity. This syndrome is particularly prevalent in post-menopausal women and its etiology is poorly understood [74]. Ji et al. [75] reported a salivary global quantitative proteomic study to identify candidate proteins biomarkers for burning mouth syndrome in a cohort of 19 patients and 19 healthy control volunteers. The study identified three overexpressed proteins viz. $\alpha$-enolase, IL-18 and kallikrein-13, as potential markers for the burning mouth syndrome.

\subsection{Recurrent Aphthous Ulceration (RAS)}

RAS is a common oral pathology recognized by ulcers in the mucosal lining of lip, tongue and soft palate. Sometimes, it also occurs at places as the isometric mucosa of the hard palate. Li et al. [76] 
identified dysregulated tryptophan and steroid hormone metabolism as a signature of the RAS in study cohort of 94 individuals (RAS $=45$, Control $=49$ ) by employing LC-MS/MS. This dysregulation of tryptophan metabolism and the hormonal imbalance are plausible causes for the depression, stress and reduced salivary immunity among RAS patients.

\section{Salivary Volatomics}

In the previous section, a significant number of studies identifying potential biomarkers for ODs were discussed. That included mostly higher molecular-weight constituents such as proteins. This section will focus specifically on the subset of potential biomarkers for ODs that are the volatile organic compounds (VOCs).

Saliva as most biofluids, also contains VOCs in its composition. Currently VOCs are being explored as potential biomarkers for ODs. Furthermore, many of them have been also detected in other biofluids [77-81], a fact that it is very important because it adds relevant information to our understanding of human metabolism in health and disease. This has obviously applications to a myriad of clinical conditions, as malignancies, infections, cardiovascular problems or genetic disorders (reviewed in Malathi, et al. [82]). This review will focus only the ODs.

Table 1. Relevant salivary VOCs with potential for oral disease discrimination.

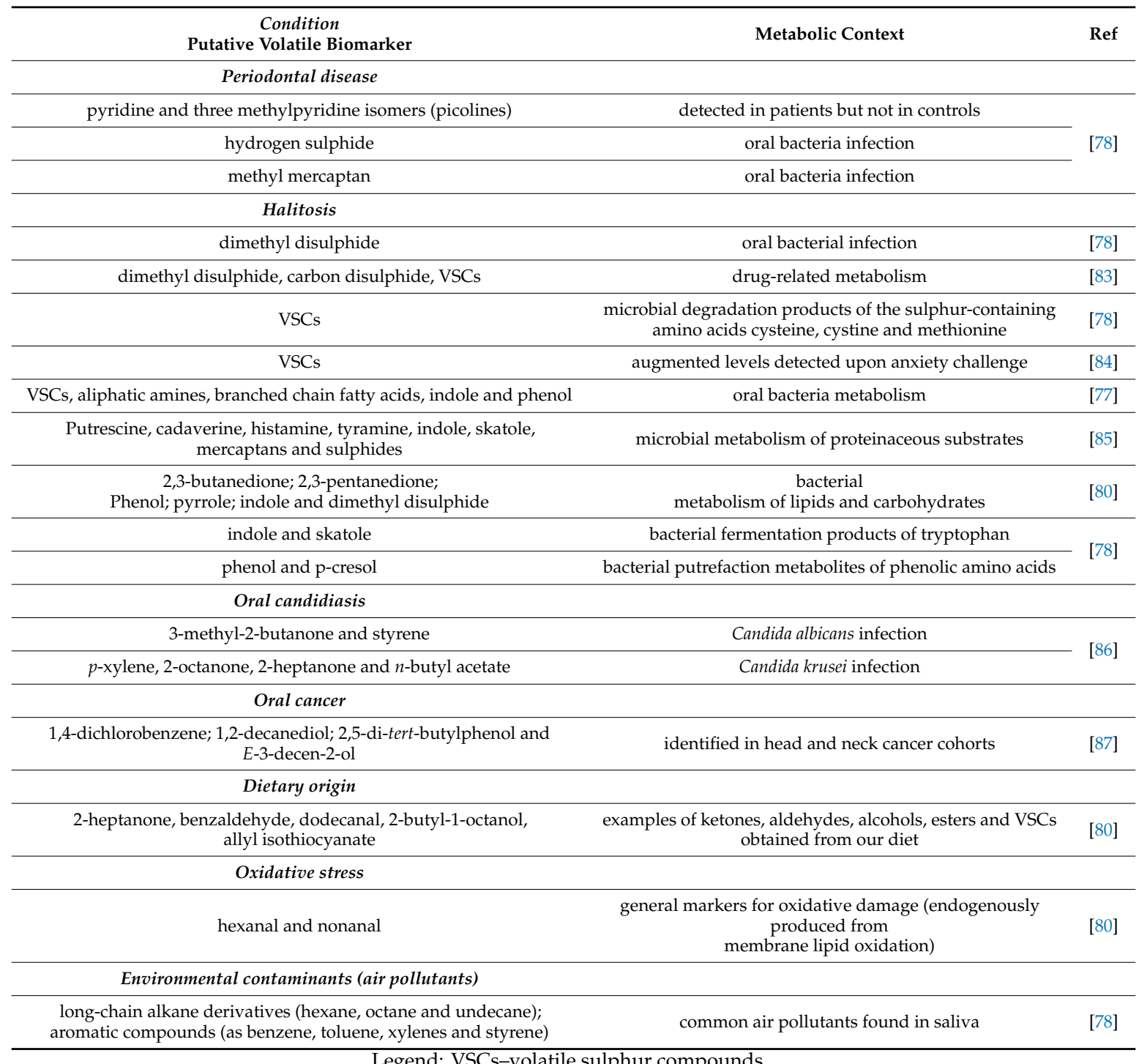


According to the most recent data reviewed by Milanowski, Pomastowski, Ligor and Buszewski [78] almost 500 VOCs have been identified in the oral cavity. This includes data from reference studies as the human volatilome showing that 359 out of 1840 VOCs were identified in the saliva [79] and the 317 VOCs identified in a 10-days follow up salivary analysis [80]. In another study, 90 out of 166 VOCs were found common to saliva and axillary sweat samples [81]. Overall, salivary VOCs derive from different sources; a part of them results from the metabolic activity of different cells in the body (review in [78]) that eventually reach the serum, blood, gingival exudate, nasal cavity or the gastrointestinal reflux, among others. The acinar cells that compose the salivary glands for instance, are highly vascularized allowing the exchange of blood components including VOCs through different mechanisms as passive diffusion, ultrafiltration and active diffusion $[16,88,89]$. However, the oral microbiota activity as well as food debris, commercial products (toothpaste for instance) and environmental contaminants have a significant contribution to the VOCs identified in saliva. The oral cavity seems to be colonized by a huge number of bacteria (50 to 100 billion bacteria from 300 to 700 different species $[81,90,91])$. In fact, there are many salivary VOCs such as aliphatic amines, branched chain fatty acids, 2,3-butanedione, 2,3-pentanedione, pyrrole, indole, phenol, and volatile Sulphur-containing compounds (VSCs, as hydrogen sulphide, methyl mercaptan, dimethyl sulphide and dimethyl disulphide) that are produced by oral bacteria $[78,80,81,91]$. In turn, the hydrocarbons which are consistently the most abundant salivary VOCs reflect their possible origin in food, fragrances and cosmetics. Finally, many of the long-chain alkane derivatives such as hexane, octane and undecane are probably environmental contaminants (air pollutants). The same applies to aromatic compounds, as benzene, toluene, xylenes and styrene [78]. This metabolic characterization of the source of the VOCs identified in saliva (synthetized in Table 1) is crucial for diagnostic purposes. In the context of the ODs, it is of paramount importance to know the source of a given VOC so we can infer if certain clinical condition is present and retain information about its progression or response to treatment. The identification of microorganisms using their volatile metabolic activity has been already reported for several clinical conditions, including pulmonary bacterial infections caused by Escherichia coli, Pseudomonas aeruginosa, Staphylococcus aureus and Klebsiella pneumoniae [92] as well as for Candida fungus causing oral candidiasis [86] (Table 1). Unique VOCs signatures for bacteria species that often colonize our mouth, S. mutans, L. salivarius and P. acidifaciens ([93]) have been also described. These in vitro studies clearly point to the potential of salivary VOCs as putative biomarkers for ODs. In fact, several features have been associated with periodontal disease, as increased amounts of VSCs and presence of pyridines, which are absent in the saliva of healthy controls [78]. These are, nevertheless, VOCs that can arise from different pathways and sources and it is likely that many confounding factors are affecting the reported results. Also, dimethyl disulphide has been associated to halitosis and different metabolites such as indole and skatole or phenol and p-cresol have been shown to be specific of the bacterial fermentation of tryptophan and phenolic amino acids, respectively (Table 1 , reviewed in [78]). There is an obvious interplay between periodontal disease and halitosis because patients affected by periodontal disease are at higher risk for halitosis detection than healthy individuals. In fact, it has been reported that the posterior portion of the tongue dorsum constitutes an important source of odorous compounds, possibly produced by $P$. gingivalis identified in these patients [94]. Nevertheless, careful analysis of such data should be taken because alternative sources such as diet, environmental contamination or even other endogenous contributions may drive variations in some of these VOCs. Blood borne halitosis for instance, is caused by malodourous compounds generated elsewhere in the organism, carried through the blood stream to the lungs where they diffuse across the pulmonary alveolar membrane to enter the breath. Regarding this, Torsten, Gomez-Moreno and Aguilar-Salvatierra [83] reported that the metabolism of at least nine medications can release dimethyl sulphide, carbon disulphide and several VSCs in breath causing a drug-related halitosis. Moreover, the metabolism of penicillamine raises the $\mathrm{pH}$ level favouring the proliferation of gram-negative bacteria in the oral cavity which in turn causes halitosis. Therefore, these forms of halitosis are not 
caused by any specific disease in the oral cavity. Anxiety is another condition that can favour changes in oral microbiota leading to significant variations in oral VSCs and consequently halitosis [84].

Cancer development and progression causes metabolic shifts that can be detected in different biofluids, including in saliva [52]. In this regard, volatomic fingerprints able to discriminate BC from healthy individuals have been already proposed $[95,96]$. Taware et al. applied the same principle to oral cancer and analysed the salivary volatile composition of a small cohort of 32 oral cancer patients and 27 controls. The authors reported that the volatiles 1,4-dichlorobenzene, 1,2-decanediol, 2,5-bis1,1-dimethylethylphenol and E-3-decen-2-ol were significantly associated with the malignant disease, possessing an excellent discriminatory potential [87].

\section{Analytical Platforms Used in the Volatomic Analysis of Saliva}

\subsection{GC-MS}

Gas chromatography hyphenated with mass spectrometry (GC-MS) is one of most popular analytical platforms for volatile metabolite profiling and considered as the "gold standard" of metabolomic research. As the name suggests, in this methodology the volatile metabolites are loaded in the GC column and the separated metabolites then detected by MS. The sample volatiles can be preconcentrated using various approaches such as Solid Phase Micro Extraction (SPME) or Needle Trap Micro Extraction (NTME), desorbed in the GC, separated and detected $[87,95,97]$. The samples that are not volatile under normal conditions can be derivatized to make the metabolites thermostable and gaseous at higher temperature.

\subsubsection{Solid Phase Micro Extraction (SPME)}

SPME is the most popular extraction methodology for the analysis of VOCs. A polymer coated fused silica fibre is exposed to the headspace of the sample vial containing the biospecimen, which can be solid or liquid. The SPME fibres are available in various thicknesses $(65 \mu \mathrm{m}$, $75 \mu \mathrm{m}, 85 \mu \mathrm{m}, 100 \mu \mathrm{m}$ ) and polymer coatings (polydimethylsiloxane, polyacrylate, divinylbenzene, carboxen and binary and ternary mixtures of these coatings). Often, to broaden the metabolic coverage polymer coats differing in their adsorption properties such as carboxen/polydimethylsiloxane or polydimethylsiloxane/divinylbenzene, can be combined in a single fibre. The VOCs accumulated in the headspace of the vial adsorb on to the SPME fibre and this interaction is dependent on the equilibrium between the sample headspace and the stationary phase. Sample conditions can be modulated to achieve a faster equilibrium by enhancing the volatile mass transfer from bulk solution to the headspace. This can be achieved by optimizing several parameters such as $\mathrm{pH}$, temperature, time, agitation speed, ionic strength and sample amount $[98,99]$. Following VOCs extraction, the adsorbed/absorbed metabolites are thermally desorbed in the GC inlet that is maintained at higher temperature to favour the VOCs release into the injection chamber and transferred to the capillary column by high purity carrier gas such as helium. The capillary columns are made up of various materials to selectively retain VOCs of different polarity. The VOCs retained on the column elute at specific temperature gradient and are carried to the MS system for compound identification. There is however, an important constrain in the use of SPME which refers to sample storage. SPME is not particularly tailored to store the trapped VOCs for long periods and samples should be analysed readily after extraction. Therefore, when analysing large sample cohorts using automatic extraction systems coupled to the following analytical platforms, the use of a rigorous quality control of quantification will be essential to mitigate batch to batch variations. A deeper review of such strategies can be inferred from the work of Saigusa, et al. [100] devoted to the concept of quality control of multiple batches for LC-MS-based quantification. Overall, the SPME approach is easy to use, sensitive (limits of detections in ppb range), reproducible and conserve the integrity of the biological sample [101]. Therefore, it's not surprising to find that SPME is widely used in volatomic analysis of various biospecimens [99,101-104]. An overview about the typical experimental layout for the analysis of salivary VOCs using SPME-GC/MS is provided 
in Figure 2. Further variations to this scheme are discussed in the following sections and refer to different microextractions approaches and analytical configurations. The goal will be the identification and validation of salivary VOCs as biomarkers for a given condition and subsequent design of POCT devices able to provide fast, reliable and near real-time analysis of such biomarkers in the clinical environment.

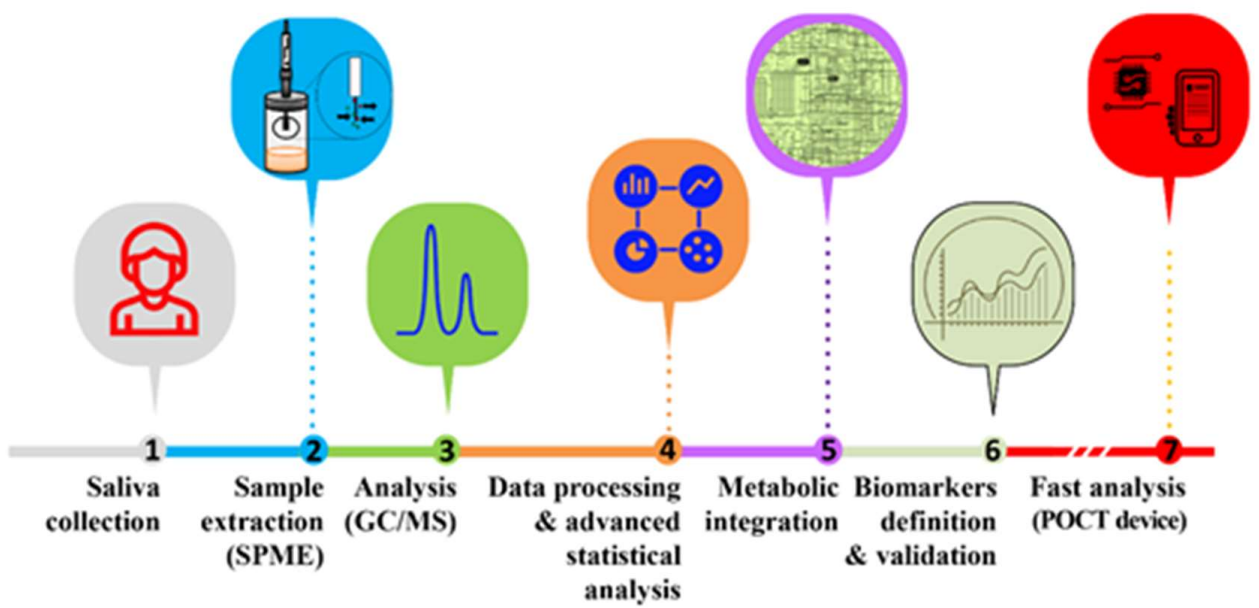

Figure 2. Typical experimental layout for the analysis of salivary VOCs and identification of putative volatile biomarkers for the clinical environment using POCT devices $([95,96])$.

\subsubsection{Needle Trap Micro Extraction (NTME)}

NTME constitutes an improvement over SPME in which the adsorbent polymer is packed inside a needle [105]. As in SPME, the adsorbent polymer of various affinities (polar, semi polar or non-polar) can be layered sequentially to increase the VOCs coverage. However, the NTME approach offers added advantages such as enhanced sensitivity and storage of sampled metabolites in the same device $[97,105,106]$. Experimentally, the VOCs are sampled by passing headspace air through the sorbent packed needle using a disposable syringe of appropriate volume. The remaining steps of chromatographic separation and MS detection of VOCs are similar to the SPME. NTME will certainly be very helpful for many applications, particularly those involving field sampling.

\subsubsection{Thin Film Micro Extraction (TFME)}

TFME employs a sheet of adsorbent polymer for extraction of VOCs from relevant biospecimens [107]. This format allows a higher extraction efficiency due to the larger surface area available for adsorption. Consequently, an enhanced VOCs preconcentration within a shorter time span can be obtained [108]. TFME, however requires a modified desorption chamber to desorb and transfer the trapped VOCs to the GC column.

\subsubsection{Stir Bar Sorptive Extraction (SBSE)}

SBSE is a sample enrichment sortion-based technique involving the use of a magnetic device under the floating sampling technology concept $[109,110]$. This enables the direct microextraction of a myriad of compounds from almost all type of matrices [110], including VOCs and semi-VOCs from saliva [81,111]. Furthermore, the membrane that covers the floating device is totally customizable to match the properties of the target analytes to extract. For this reason, there is nowadays a wide range of variations to SBSE, although generically using the same operation concepts of a magnetic-driven floating device. 


\subsection{Direct Injection Mass Spectrometry}

Direct injection mass spectrometry has been also employed in the detection of low abundant VOCs from different biospecimens. The analytical platforms that allow this approach are mainly Proton Transfer Reaction-Mass Spectrometry (PTR-MS), Selected Ion Flow Tube-Mass Spectrometry (SIFT-MS) and Secondary Electrospray Ionization-Mass Spectrometry (SESI-MS) [112-115]. The PTR-MS is based on the generation of $\mathrm{H}_{3} \mathrm{O}^{+}$ion from high purity water source which subsequently ionize the target analytes by transferring protons. Then, the ionized metabolite can be detected by various MS analysers such as TOF or quadrupole.

However, the $\mathrm{H}_{3} \mathrm{O}^{+}$soft-ionization mode enables ionization of only metabolites with higher proton affinity than water, the recent advances in PTR-MS and in SIFT-MS also offer the switching-reagent-ion mode. This produces several precursor ions $\left(\mathrm{H}_{3} \mathrm{O}^{+}, \mathrm{NO}^{+}\right.$, or $\left.\mathrm{O}_{2}{ }^{+}\right)$for chemical ionization of the wider variety of target analytes. Hence, a higher metabolic coverage is obtained. The advantage of direct-MS is that they perform real-time quantitative analysis of metabolites without any sample preparation steps that allows online assessment of in vivo physiology, metabolism and pathophysiology [116-118], without the time-consuming chromatographic separation steps. In turn, SESI-MS is a recently developed technique for measurements of large molecules (e.g., those appear in breath condensates) and is eventually gaining attention in metabolomic studies.

\section{3. eNOSE}

eNOSE or electronic nose is a targeted volatomic approach for artificial olfaction and often performed by various platforms such as laser spectroscopy and chemical and nano-optical sensors [68]. This technology offers several advantages over conventional approaches in Table 2 such as easy to use and transport, requires semi-skilled technical expertise, low operational costs and real time analysis $[119,120]$. Moreover, eNOSE can also be customized by integrating a gas sensing arrays of choice to suit a given application. However, this technology also suffers from several drawbacks such as low sensitivity and specificity as compared to most analytical platforms. Susceptibility to moisture interference and incapability to identify single VOCs are also important disadvantages [121].

Table 2. Selected examples of different experimental layouts used to characterize salivary VOCs.

\begin{tabular}{|c|c|c|}
\hline Experimental Layout/Condition & Relevant VOCs Identified & Ref \\
\hline \multicolumn{3}{|c|}{ HS-SPME/GC-MS } \\
\hline Breast cancer & $\begin{array}{l}\text { 3-methyl-pentanoic acid, 4-methyl-pentanoic acid, phenol and p-tert-butyl-phenol } \\
\text { (Portuguese samples) and acetic, propanoic, benzoic acids, 1,2-decanediol, } \\
\text { 2-decanone, and decanal (Indian samples) }\end{array}$ & {$[95]$} \\
\hline Control subjects & twenty-one VOCs detected in saliva samples, mostly aldehydes & [122] \\
\hline Halitosis and Submandibular Abscesses & 23 VOCs specific for halitosis and 41 for abscess & [123] \\
\hline \multicolumn{3}{|c|}{ TFME-GC/MS } \\
\hline OSCC & Twelve salivary VOCs were characteristic of OSCC patients & [108] \\
\hline \multicolumn{3}{|c|}{ HS-trap/GC-MS } \\
\hline Control subjects & 34 VOCs present in all samples analysed $(n=100)$ & [80] \\
\hline \multicolumn{3}{|c|}{ SBSE-GC/MS } \\
\hline Control subjects & $\begin{array}{l}\text { Excellent reproducibility for a wide range of salivary compounds, including } \\
\text { alcohols, aldehydes, ketones, carboxylic acids, esters, amines, amides, lactones, } \\
\text { and hydrocarbons }\end{array}$ & [81] \\
\hline Control subjects & $\begin{array}{c}\text { Comparison of individual and gender fingerprints using different biofluids (sweat, } \\
\text { urine and saliva) }\end{array}$ & [111] \\
\hline \multicolumn{3}{|c|}{ gas-diffusion flow injection analysis-GC/MS } \\
\hline & acetaldehyde & [124] \\
\hline \multicolumn{3}{|c|}{ DCM extraction and derivatization followed by GC/MS analysis } \\
\hline women & 2-Nonenal-ovulatory specific salivary VOCs throughout menstrual cycle & [125] \\
\hline
\end{tabular}




\section{Data Analysis}

The main objective of measuring different types of analytes in saliva samples is the identification of a specific pool that, at a defined concentration shows a high level of significance as putative biomarkers for the non-invasive diagnoses of different diseases [126,127]. However, to characterize this pool of analytes it is necessary to use different statistical tools to find biopatterns able to differentiate between patients and healthy individuals. The definition of the most suitable and meaningful statistical tool is very challenging. In fact, a less accurate choice can lead to extreme and undesirable diagnostic situations involving a high level of false positives and negatives. Beyond this, it is critical to have large enough cohorts to cope with the sample complexity. Too many times, the number of samples analysed is very short in comparison to the number of metabolites identified, jeopardizing the subsequent statistical analysis. Overall, it is necessary to consider a set of factors before choosing the ideal statistical tool, namely the complexity and size of the sample under study, the number of analytes and the variability within each sample set [128]. Furthermore, it is necessary to normalize the data obtained in each group to avoid errors associated with the raw data [126,128]. Traditionally, many researchers use the $p$-value as the main statistical tool in order to identify analytes whose variation is statistically significant [129-132]. However, this approach is extremely limited and often results in numerous false positives and negatives $[133,134]$. For this reason, multivariate statistical analysis (MVSA) became very popular to identify set of analytes that can be considered biomarkers of different pathologies [126-128,135]. The MVSA can be divided into two distinct categories: the unsupervised analysis, typically performed after the normalization of the data obtained; and supervised analysis, involving a deeper characterization of the relationship between variables (analytes) and cases (sample) [36,49,128,136,137].

Principal component analysis (PCA) is the most common method used in unsupervised analysis $[49,128,130,131,137]$. This approach reduces the number of associated factors by showing clusters according to the separation between groups. However, the disadvantage is that it does not show which variables are directly responsible for the formation of these clusters. Thus, and although it is possible to visualize the separation between groups, unsupervised techniques, such as the PCA, do not allow the creation of a classification model for the different variables $[35,128]$. For this reason, supervised methods become more advantageous, allowing researchers to establish important links between the sample and the variables $[35,128]$. According to the complexity of the sample and the final objective of the analysis, it is possible to use linear methods, such as linear discriminant analysis (LDA), whose objective is to determine a linear function based on the analyte matrix obtained and try to establish differences between the studied groups [128]. This approach is considered relatively quick and simple and is typically used to classify variables after PCA analysis. There are several LDA methods for the analysis of biological compounds, such as the discriminant analysis of partial least squares (PLS-DA) $[35,49,137]$. Due to its ability to distinguish between groups, identifying which compounds are responsible for each separation, PLS-DA is an extremely useful tool in understanding the metabolites that are responsible for the separation between the control and the patients groups under study $[35,49,126,128,131,136-139]$. However, it is important to note that for the success of this method, the PLS-DA must be optimized a priori [140], with its linear model being trained so that its precision is high and the errors evaluated $[126,128,139]$. On the other hand, metabolites may not respond linearly to a mathematical model [128], and this may limit the feasibility of the linear methods previously described. To overcome this issue, another supervised approach, called non-linear analysis, was proposed. This approach is relatively recent and requires a set of optimizations for the definition of the statistical model, involving the most popular methods artificial neural networks (ANNs) [141,142]. Different researchers refer this methodology as being extremely robust and with a high predictive power, since it involves a huge set of statistical methods [141,142]. ANNs present, therefore, a great potential for the saliva analysis $[143,144]$.

Finally, and regardless of the statistical methods used, the results obtained should be submitted to a final stage of validation to challenge the robustness of the method developed. This step is critical to 
evaluate the errors of the developed model and its sensitivity and specificity. Often, despite the many optional parameters involved in the different statistical tools available, default parameters are selected without proper consideration of the overfitting consequences this may have. One strategy to detect this problem more easily is to follow a double cross-validation $[139,140]$. This evaluation is measured by the classification rate of the model $[126,139,145]$. The statistical analysis is, therefore, a powerful tool for the determination of potential biomarkers, regardless of the type of analytes involved (variables), as this obviously includes ODs and the analysis of salivary VOCs.

\section{Current Challenges and Future Perspective}

Whereas the precedent section of this review explicitly elaborates the growing potential and promising future applicability of salivary volatilomics, readers should be aware of certain confounding/cofounding challenges and limitations of the same. Each omics approach involving liquid biological matrices such as blood, saliva or urine has its own potentials and weaknesses. While none of the above-mentioned biological matrices yet offered a clinically applicable volatile biomarker or marker set for routine diagnosis, all those substances, which have been discussed or referred in above sections are experimentally proposed biomarkers.

Fortunately, salivary VOCs measurement allows a non-invasive and repeated measurements without causing any additional pain/burden to subjects. In contrast to saliva, as blood sampling is invasive and painful, it might not be widely feasible towards future PoC applicability (i.e., while assuming personalized medicine), especially for a nonexpert person due to compliance issues. Especially in case of ODs, saliva acts as a proximal fluid that carries a lot of local/immediate metabolic, biochemical and/or pathophysiological information. On the other hand, presence or abundance of volatile metabolites in urine largely depend on the individual kidney function, glomerular filtration rate (GFR), bacterial flora in the urinary tract, water intake and antidiuretic hormone (ADH) activity and on the time of sampling. As the volume of urine largely depends on the intake of water and subsequent GFR, concentrations of aqueous soluble substances greatly vary within the same individual in different samples. Unlike saliva, a urinary measurement cannot be repeated whenever needed.

At present, saliva-based volatilomics also suffers from apparently unsolved problems due to ubiquitously varying confounders from the oral cavity environment. Contributions from food, beverage, smoking residuals and/or from oral microbiota are hard to differentiate. In addition, substances/metabolites with low aqueous solubility are very unlikely to pass onto saliva from the systemic circulation. Furthermore, local enzymatic (e.g., amylase, maltase, lysozyme etc.) activities within the oral cavity may give rise to many breakdown metabolites, which are hard to differentiate as exogenous (by origin) substances. As the standard secretory actions/functions of the salivary glands are still unknown, no normal range exists for saliva volume in individuals. Therefore, saliva volume and corresponding substance concentrations may vary arbitrarily in different samples from the same subject.

In order to address those issues, more systematic measures should be employed on studies concerning physiological, biochemical and/or metabolic variations of salivary volatilome in healthy population. Along with the improved analytical identification and quantification of VOCs, both sampling- and analytical standards need to be established before conducting diagnostic/screening studies on handful of subjects via applying complex statistical methods in cross-sectional mode. Advanced and hyphenated analytical applications can trace hundreds of VOCs up to low parts per trillion by volume (pptV) range, which are the independent and/or partially dependent variables (i.e., regulated by many known or unknown factors) and often employ unprecedent complexities towards reliable clinical interpretations of data. Thus, we must invest more effort on the fundamental understanding of the true origin (endogenous/exogenous, pathological/therapeutic etc.) and physiochemical properties of the volatiles in the saliva and their rational/probable clinical relationships to an oral pathology. Cross-sectionally observed differential expressions (i.e., pilot studies) in salivary volatiles must be validated/reproduced within large independent cohorts via prospective follow up. Most importantly, at such infancy of salivary omics, it is rather more important to gain 
basic knowledge on the effects of oral pathophysiological prognosis on VOCs compositions over the course of time.

We must realize our present analytical potentials, clinical knowledge and expertise in order to understand what is possible to achieve via salivary omics. Studies should avoid claims of early diagnosis via observed differential expressions of markers from patients at a late/advanced state of a disease. Understanding of appropriate statistical tools and interpretation of evaluated data are mandatory attributes to overcome many challenges and limitations. Finally, saliva is a dynamic matrix and can serve as an excellent phenotypic window for non-invasive monitoring of physiology, metabolism, oral pathophysiology and/or administered therapy. Salivary omics thus holds potential promise towards its future paths in relation to personalized medicine.

Author Contributions: P.P.-F. was responsible for Sections 2 and 6, J.A.M.P. and J.S.C. by Sections 1 and 3, J.A.M.P., R.T. and S.R. collaborate on Section 4. Section 5 was prepared by R.T., S.R. and P.S. Section 7 is contributed by P.S. All authors read and revised the manuscript and J.A.M.P. made its edition and submission. All authors have read and agreed to the published version of the manuscript.

Funding: This work was supported by FCT-Fundação para a Ciência e a Tecnologia through the CQM Base Fund-UIDB/00674/2020, and Programmatic Fund-UIDP/00674/2020, and by ARDITI-Agência Regional para o Desenvolvimento da Investigação Tecnologia e Inovação, through the project M1420 01-0145-FEDER-000005-Centro de Química da Madeira-CQM+ (Madeira 14-20 Program), and the Inno-INDIGO NCDs-CAPomics project, Department of Science \& Technology, Govt. of India, grant no. DST/IMRCD/EU/Inno-Indigo/NCDs-CAPomics/2015. PPF was supported by FCT (PhD fellowship SFRH/BD/129630/2017) and JAMP by ARDITI (Post-Doctoral fellowship Project M1420-09-5369-FSE-000001). PS is grateful for the financial support of the Inno-INDIGO NCDs-CAPomics Project (BMBF 01DQ16010).

Acknowledgments: R.T. acknowledges the Council of Scientific and Industrial Research, New Delhi, India for research associateship.

Conflicts of Interest: The authors declare no conflict of interest.

\section{Abbreviations}

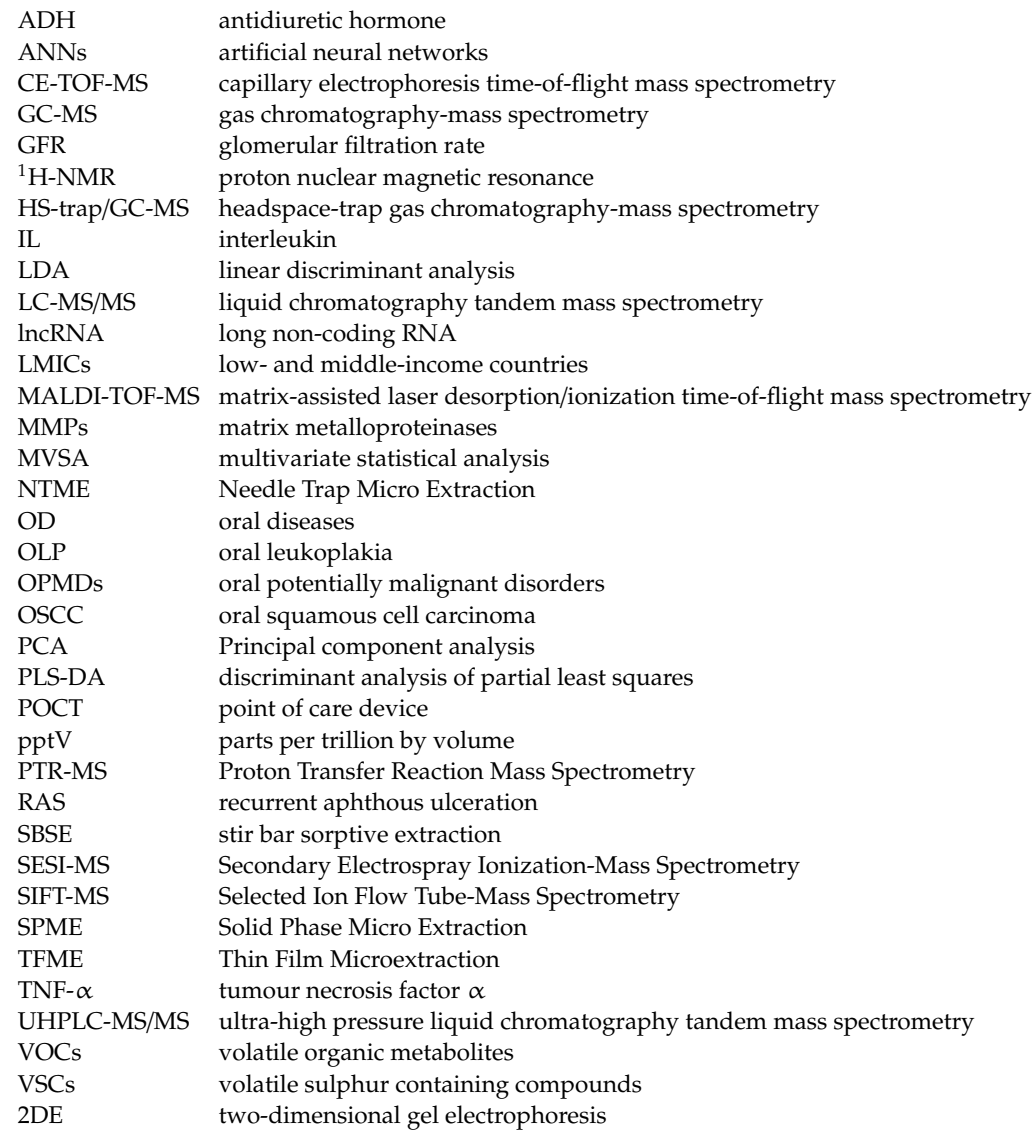




\section{References}

1. $\quad$ Peres, M.A.; Macpherson, L.M.D.; Weyant, R.J.; Daly, B.; Venturelli, R.; Mathur, M.R.; Listl, S.; Celeste, R.K.; Guarnizo-Herreno, C.C.; Kearns, C.; et al. Oral diseases: A global public health challenge. Lancet 2019, 394, 249-260. [CrossRef]

2. Dawes, C.; Wong, D.T.W. Role of Saliva and Salivary Diagnostics in the Advancement of Oral Health. J. Dent. Res. 2019, 98, 133-141. [CrossRef]

3. Deepa, T.; Thirrunavukkarasu, N. Saliva as a potential diagnostic tool. Indian J. Med. Sci. 2010, 64, $293-306$. [CrossRef]

4. Katsani, K.R.; Sakellari, D. Saliva proteomics updates in biomedicine. J. Biol. Res. 2019, 26, 17. [CrossRef] [PubMed]

5. Bellagambi, F.G.; Lomonaco, T.; Salvo, P.; Vivaldi, F.; Hangouët, M.; Ghimenti, S.; Biagini, D.; Di Francesco, F.; Fuoco, R.; Errachid, A. Saliva sampling: Methods and devices. An overview. Tractrends Anal. Chem. 2020, 124, 115781. [CrossRef]

6. Farnaud, S.J.; Kosti, O.; Getting, S.J.; Renshaw, D. Saliva: Physiology and diagnostic potential in health and disease. Sci. World J. 2010, 10, 434-456. [CrossRef]

7. Gardner, A.; Carpenter, G.; So, P.W. Salivary metabolomics: From diagnostic biomarker discovery to investigating biological function. Metabolites 2020, 10, 47. [CrossRef]

8. Aps, J.K.; Martens, L.C. Review: The physiology of saliva and transfer of drugs into saliva. Forensic Sci. Int. 2005, 150, 119-131. [CrossRef]

9. Papacosta, E.; Nassis, G.P. Saliva as a tool for monitoring steroid, peptide and immune markers in sport and exercise science. J. Sci. Med. Sport 2011, 14, 424-434. [CrossRef]

10. Edgar, W.; O’Mullane, D.; Dawes, C. Saliva and Oral Health; British Dental Association: London, UK, 2004; Volume 146.

11. Sugimoto, M.; Saruta, J.; Matsuki, C.; To, M.; Onuma, H.; Kaneko, M.; Soga, T.; Tomita, M.; Tsukinoki, K. Physiological and environmental parameters associated with mass spectrometry-based salivary metabolomic profiles. Metabolomics 2013, 9, 454-463. [CrossRef]

12. Ishikawa, S.; Sugimoto, M.; Kitabatake, K.; Tu, M.; Sugano, A.; Yamamori, I.; Iba, A.; Yusa, K.; Kaneko, M.; Ota, S.; et al. Effect of timing of collection of salivary metabolomic biomarkers on oral cancer detection. Amino Acids 2017, 49, 761-770. [CrossRef]

13. Lamy, E.; Mau, M. Saliva proteomics as an emerging, non-invasive tool to study livestock physiology, nutrition and diseases. J. Proteom. 2012, 75, 4251-4258. [CrossRef] [PubMed]

14. Gröschl, M. Saliva: A reliable sample matrix in bioanalytics. Bioanalysis 2017, 9, 655-668. [CrossRef] [PubMed]

15. Proctor, G.B. The physiology of salivary secretion. Periodontol. 2000 2016, 70, 11-25. [CrossRef] [PubMed]

16. Pereira, J.A.M.; Taware, R.; Porto-Figueira, P.; Rapole, S.; Câmara, J.S. Chapter 29-The salivary volatome in breast cancer. In Precision Medicine for Investigators, Practitioners and Providers; Faintuch, J., Faintuch, S., Eds.; Academic Press: Cambridge, MA, USA, 2020; pp. 301-307. [CrossRef]

17. Bray, F.; Ferlay, J.; Soerjomataram, I.; Siegel, R.L.; Torre, L.A.; Jemal, A. Global cancer statistics 2018: GLOBOCAN estimates of incidence and mortality worldwide for 36 cancers in 185 countries. CA Cancer J. Clin. 2018, 68, 394-424. [CrossRef] [PubMed]

18. Amado, F.M.L.; Ferreira, R.P.; Vitorino, R. One decade of salivary proteomics: Current approaches and outstanding challenges. Clin. Biochem. 2013, 46, 506-517. [CrossRef]

19. Amado, F.M.L.; Vitorino, R.M.P.; Domingues, P.M.D.N.; Lobo, M.J.C.; Duarte, J.A.R. Analysis of the human saliva proteome. Expert Rev. Proteomics 2005, 2, 521-539. [CrossRef]

20. Cong, X.; Zhang, Y.; He, Q.H.; Wei, T.; Zhang, X.M.; Zhang, J.Z.; Xiang, R.L.; Yu, G.Y.; Wu, L.L. Endothelial Tight Junctions Are Opened in Cholinergic-Evoked Salivation in Vivo. J. Dent. Res. 2017, 96, 562-570. [CrossRef]

21. Simón-Soro, Á.; Tomás, I.; Cabrera-Rubio, R.; Catalan, M.D.; Nyvad, B.; Mira, A. Microbial geography of the oral cavity. J. Dent. Res. 2013, 92, 616-621. [CrossRef]

22. Azen, E.A.; Goodman, P.A.; Lalley, P.A. Human salivary proline-rich protein genes on chromosome 12. Am. J. Hum. Genet. 1985, 37, 418-424. 
23. Castagnola, M.; Cabras, T.; Vitali, A.; Sanna, M.T.; Messana, I. Biotechnological implications of the salivary proteome. Trends Biotechnol. 2011, 29, 409-418. [CrossRef]

24. Pihlstrom, B.L.; Michalowicz, B.S.; Johnson, N.W. Periodontal diseases. Lancet 2005, 366, $1809-1820$. [CrossRef]

25. Gonçalves, L.D.R.; Soares, M.R.; Nogueira, F.C.S.; Garcia, C.H.S.; Camisasca, D.R.; Domont, G.; Feitosa, A.C.R.; Pereira, D.A.; Zingali, R.B.; Alves, G. Analysis of the salivary proteome in gingivitis patients. J. Periodontal Res. 2011, 46, 599-606. [CrossRef] [PubMed]

26. Chan, H.H.; Rahim, Z.H.A.; Jessie, K.; Hashim, O.H.; Taiyeb-Ali, T.B. Salivary proteins associated with periodontitis in patients with type 2 diabetes mellitus. Int. J. Mol. Sci. 2012, 13, 4652-4654. [CrossRef] [PubMed]

27. Gonçalves, L.D.R.; Soares, M.R.; Nogueira, F.C.S.; Garcia, C.; Camisasca, D.R.; Domont, G.; Feitosa, A.C.R.; Pereira, D.d.A.; Zingali, R.B.; Alves, G. Comparative proteomic analysis of whole saliva from chronic periodontitis patients. J. Proteom. 2010, 73, 1334-1341. [CrossRef]

28. Rangé, H.; Léger, T.; Huchon, C.; Ciangura, C.; Diallo, D.; Poitou, C.; Meilhac, O.; Bouchard, P.; Chaussain, C. Salivary proteome modifications associated with periodontitis in obese patients. J. Clin. Periodontol. 2012, 39, 799-806. [CrossRef]

29. Wu, Y.; Shu, R.; Luo, L.J.; Ge, L.H.; Xie, Y.F. Initial comparison of proteomic profiles of whole unstimulated saliva obtained from generalized aggressive periodontitis patients and healthy control subjects. J. Periodontal Res. 2009, 44, 636-644. [CrossRef]

30. Bostanci, N.; Selevsek, N.; Wolski, W.; Grossmann, J.; Bao, K.; Wahlander, A.; Trachsel, C.; Schlapbach, R.; Oztürk, V.Ö.; Afacan, B.; et al. Targeted proteomics guided by label-free quantitative proteome analysis in saliva reveal transition signatures from health to periodontal disease. Mol. Cell. Proteom. 2018, 17, 1392-1409. [CrossRef]

31. Sorsa, T.; Gursoy, U.K.; Nwhator, S.; Hernandez, M.; Tervahartiala, T.; Leppilahti, J.; Gursoy, M.; Könönen, E.; Emingil, G.; Pussinen, P.J.; et al. Analysis of matrix metalloproteinases, especially MMP-8, in gingival creviclular fluid, mouthrinse and saliva for monitoring periodontal diseases. Periodontol. 2000 2016, 70, 142-163. [CrossRef]

32. Emecen-Huja, P.; Hasan, I.; Miller, C.S. Biologic markers of failing implants. Dent. Clin. North Am. 2015, 59, 179-194. [CrossRef]

33. Gursoy, U.K.; Kononen, E.; Pussinen, P.J.; Tervahartiala, T.; Hyvarinen, K.; Suominen, A.L.; Uitto, V.J.; Paju, S.; Sorsa, T. Use of host- and bacteria-derived salivary markers in detection of periodontitis: A cumulative approach. Dis. Markers 2011, 30, 299-305. [CrossRef] [PubMed]

34. Kaczynski, T.; Wronski, J.; Gluszko, P.; Kryczka, T.; Miskiewicz, A.; Gorski, B.; Radkowski, M.; Strzemecki, D.; Grieb, P.; Gorska, R. Salivary interleukin 6, interleukin 8, interleukin 17A, and tumour necrosis factor alpha levels in patients with periodontitis and rheumatoid arthritis. Cent. Eur. J. Immunol. 2019, 44, 269-276. [CrossRef] [PubMed]

35. Aimetti, M.; Cacciatore, S.; Graziano, A.; Tenori, L. Metabonomic analysis of saliva reveals generalized chronic periodontitis signature. Metabolomics 2012, 8, 465-474. [CrossRef]

36. Gawron, K.; Wojtowicz, W.; Łazarz-Bartyzel, K.; Łamasz, A.; Qasem, B.; Mydel, P.; Chomyszyn-Gajewska, M.; Potempa, J.; Mlynarz, P. Metabolomic status of the oral cavity in chronic periodontitis. Vivo 2019, 33, 1165-1174. [CrossRef]

37. Romano, F.; Meoni, G.; Manavella, V.; Baima, G.; Tenori, L.; Cacciatore, S.; Aimetti, M. Analysis of salivary phenotypes of generalized aggressive and chronic periodontitis through nuclear magnetic resonance-based metabolomics. J. Periodontol. 2018, 89, 1452-1460. [CrossRef] [PubMed]

38. Rzeznik, M.; Triba, M.N.; Levy, P.; Jungo, S.; Botosoa, E.; Duchemann, B.; Le Moyec, L.; Bernaudin, J.F.; Savarin, P.; Guez, D. Identification of a discriminative metabolomic fingerprint of potential clinical relevance in saliva of patients with periodontitis using $1 \mathrm{H}$ nuclear magnetic resonance (NMR) spectroscopy. PLoS ONE 2017, 12. [CrossRef]

39. Singh, M.P.; Saxena, M.; Saimbi, C.S.; Arif, J.M.; Roy, R. Metabolic profiling by 1H NMR spectroscopy of saliva shows clear distinction between control and diseased case of periodontitis. Metabolomics 2017, 13. [CrossRef] 
40. Liebsch, C.; Pitchika, V.; Pink, C.; Samietz, S.; Kastenmüller, G.; Artati, A.; Suhre, K.; Adamski, J.; Nauck, M.; Völzke, H.; et al. The Saliva Metabolome in Association to Oral Health Status. J. Dent. Res. 2019, 98, 642-651. [CrossRef]

41. Huang, Y.; Zhu, M.; Li, Z.; Sa, R.; Chu, Q.; Zhang, Q.; Zhang, H.; Tang, W.; Zhang, M.; Yin, H. Mass spectrometry-based metabolomic profiling identifies alterations in salivary redox status and fatty acid metabolism in response to inflammation and oxidative stress in periodontal disease. Free Radic. Biol. Med. 2014, 70, 223-232. [CrossRef]

42. Ebersole, J.L.; Nagarajan, R.; Akers, D.; Miller, C.S. Targeted salivary biomarkers for discrimination of periodontal health and disease(s). Front. Cell. Infect. Microbiol. 2015, 5, 62. [CrossRef]

43. Hussain, Q.A.; McKay, I.J.; Gonzales-Marin, C.; Allaker, R.P. Detection of adrenomedullin and nitric oxide in different forms of periodontal disease. J. Periodontal Res. 2016, 51, 16-25. [CrossRef] [PubMed]

44. O'Brien-Simpson, N.M.; Burgess, K.; Brammar, G.C.; Darby, I.B.; Reynolds, E.C. Development and evaluation of a saliva-based chair-side diagnostic for the detection of Porphyromonas gingivalis. J. Oral Microbiol. 2015, 7, 29129. [CrossRef] [PubMed]

45. Pitts, N.B.; Zero, D.T.; Marsh, P.D.; Ekstrand, K.; Weintraub, J.A.; Ramos-Gomez, F.; Tagami, J.; Twetman, S.; Tsakos, G.; Ismail, A. Dental caries. Nat. Rev. Dis. Primers 2017, 3, 17030. [CrossRef] [PubMed]

46. Zhang, C.Z.; Cheng, X.Q.; Li, J.Y.; Zhang, P.; Yi, P.; Xu, X.; Zhou, X.D. Saliva in the diagnosis of diseases. Int. J. Oral Sci. 2016, 8, 133-137. [CrossRef]

47. Fiorillo, L.; Cervino, G.; Laino, L.; D'Amico, C.; Mauceri, R.; Tozum, T.F.; Gaeta, M.; Cicciu, M. Porphyromonas gingivalis, Periodontal and Systemic Implications: A Systematic Review. Dent. J. (Basel) 2019, 7, 114. [CrossRef] [PubMed]

48. Vitorino, R.; De Morais Guedes, S.; Ferreira, R.; Lobo, M.J.C.; Duarte, J.; Ferrer-Correia, A.J.; Tomer, K.B.; Domingues, P.M.; Amado, F.M.L. Two-dimensional electrophoresis study of in vitro pellicle formation and dental caries susceptibility. Eur. J. Oral Sci. 2006, 114, 147-153. [CrossRef]

49. Fidalgo, T.K.S.; Freitas-Fernandes, L.B.; Angeli, R.; Muniz, A.M.S.; Gonsalves, E.; Santos, R.; Nadal, J.; Almeida, F.C.L.; Valente, A.P.; Souza, I.P.R. Salivary metabolite signatures of children with and without dental caries lesions. Metabolomics 2013, 9, 657-666. [CrossRef]

50. Chaturvedi, A.K.; Udaltsova, N.; Engels, E.A.; Katzel, J.A.; Yanik, E.L.; Katki, H.A.; Lingen, M.W.; Silverberg, M.J. Oral leukoplakia and risk of progression to oral cancer: A population-based cohort study. J. Natl. Cancer Inst. 2019. [CrossRef]

51. Zotti, F.; Nocini, R.; Capocasale, G.; Fior, A.; Peretti, M.; Albanese, M. Malignant transformation evidences of Oral Lichen Planus: When the time is of the essence. Oral Oncol. 2020, 104594. [CrossRef]

52. Sugimoto, M.; Wong, D.T.; Hirayama, A.; Soga, T.; Tomita, M. Capillary electrophoresis mass spectrometry-based saliva metabolomics identified oral, breast and pancreatic cancer-specific profiles. Metabolomics 2010, 6, 78-95. [CrossRef]

53. Ishikawa, S.; Sugimoto, M.; Kitabatake, K.; Sugano, A.; Nakamura, M.; Kaneko, M.; Ota, S.; Hiwatari, K.; Enomoto, A.; Soga, T.; et al. Identification of salivary metabolomic biomarkers for oral cancer screening. Sci. Rep. 2016, 6. [CrossRef]

54. Ishikawa, S.; Sugimoto, M.; Edamatsu, K.; Sugano, A.; Kitabatake, K.; Iino, M. Discrimination of oral squamous cell carcinoma from oral lichen planus by salivary metabolomics. Oral Dis. 2020, 26, 35-42. [CrossRef] [PubMed]

55. Wei, J.; Xie, G.; Zhou, Z.; Shi, P.; Qiu, Y.; Zheng, X.; Chen, T.; Su, M.; Zhao, A.; Jia, W. Salivary metabolite signatures of oral cancer and leukoplakia. Int. J. Cancer 2011, 129, 2207-2217. [CrossRef] [PubMed]

56. Wang, Q.; Gao, P.; Wang, X.; Duan, Y. The early diagnosis and monitoring of squamous cell carcinoma via saliva metabolomics. Sci. Rep. 2014, 4. [CrossRef] [PubMed]

57. Lohavanichbutr, P.; Zhang, Y.; Wang, P.; Gu, H.; Nagana Gowda, G.A.; Djukovic, D.; Buas, M.F.; Raftery, D.; Chen, C. Salivary metabolite profiling distinguishes patients with oral cavity squamous cell carcinoma from normal controls. PLOS ONE 2018, 13. [CrossRef]

58. Balkwill, F.; Mantovani, A. Inflammation and cancer: Back to Virchow? Lancet 2001, 357, 539-545. [CrossRef]

59. Aziz, S.; Ahmed, S.S.; Ali, A.; Khan, F.A.; Zulfiqar, G.; Iqbal, J.; Khan, A.A.; Shoaib, M. Salivary Immunosuppressive Cytokines IL-10 and IL-13 Are Significantly Elevated in Oral Squamous Cell Carcinoma Patients. Cancer Invest. 2015, 33, 318-328. [CrossRef] 
60. Dowling, P.; Wormald, R.; Meleady, P.; Henry, M.; Curran, A.; Clynes, M. Analysis of the saliva proteome from patients with head and neck squamous cell carcinoma reveals differences in abundance levels of proteins associated with tumour progression and metastasis. J. Proteom. 2008, 71, 168-175. [CrossRef] [PubMed]

61. Honarmand, M.; Farhad-Mollashahi, L.; Nakhaee, A.; Nehi, M. Salivary levels of ErbB2 and CEA in oral squamous cell carcinoma patients. Asian Pac. J. Cancer Prev. 2016, 17, 77-80. [CrossRef] [PubMed]

62. Jou, Y.J.; Lin, C.D.; Lai, C.H.; Tang, C.H.; Huang, S.H.; Tsai, M.H.; Chen, S.Y.; Kao, J.Y.; Lin, C.W. Salivary zinc finger protein 510 peptide as a novel biomarker for detection of oral squamous cell carcinoma in early stages. Clin. Chim. Acta 2011, 412, 1357-1365. [CrossRef] [PubMed]

63. Hu, S.; Arellano, M.; Boontheung, P.; Wang, J.; Zhou, H.; Jiang, J.; Elashoff, D.; Wei, R.; Loo, J.A.; Wong, D.T. Salivary proteomics for oral cancer biomarker discovery. Clin. Cancer Res. 2008, 14, 6246-6252. [CrossRef] [PubMed]

64. Yu, J.S.; Chen, Y.T.; Chiang, W.F.; Hsiao, Y.C.; Chu, L.J.; Seei, L.C.; Wu, C.S.; Tu, H.T.; Chen, H.W.; Chen, C.C.; et al. Saliva protein biomarkers To detect oral squamous cell carcinoma in a high-risk population in Taiwan. Proc. Natl. Acad. Sci. USA 2016, 113, 11549-11554. [CrossRef] [PubMed]

65. Sivadasan, P.; Gupta, M.K.; Sathe, G.; Sudheendra, H.V.; Sunny, S.P.; Renu, D.; Hari, P.S.; Gowda, H.; Suresh, A.; Kuriakose, M.A.; et al. Salivary proteins from dysplastic leukoplakia and oral squamous cell carcinoma and their potential for early detection. J. Proteom. 2020, 212, 103574. [CrossRef]

66. Dos Santos, E.S.; Ramos, J.C.; Normando, A.G.C.; Mariano, F.V.; Paes Leme, A.F. Epigenetic alterations in salivary gland tumors. Oral Dis. 2019. [CrossRef] [PubMed]

67. Li, C.; Ye, J.; Zhang, Z.; Gong, Z.; Lin, Z.; Ding, M. Long non-coding RNA RBM5-AS1 promotes the aggressive behaviors of oral squamous cell carcinoma by regulation of miR-1285-3p/YAP1 axis. Biomed. Pharm. 2020, 123, 109723. [CrossRef] [PubMed]

68. Park, N.J.; Zhou, H.; Elashoff, D.; Henson, B.S.; Kastratovic, D.A.; Abemayor, E.; Wong, D.T. Salivary microRNA: Discovery, characterization, and clinical utility for oral cancer detection. Clin. Cancer Res. 2009, 15, 5473-5477. [CrossRef] [PubMed]

69. Lodi, G.; Carrozzo, M.; Furness, S.; Thongprasom, K. Interventions for treating oral lichen planus: A systematic review. Br. J. Derm. 2012, 166, 938-947. [CrossRef]

70. Lorenzo-Pouso, A.I.; Pérez-Sayáns, M.; Bravo, S.B.; López-Jornet, P.; García-Vence, M.; Alonso-Sampedro, M.; Carballo, J.; García-García, A.; Zalewska, A. Protein-Based Salivary Profiles as Novel Biomarkers for Oral Diseases. Dis. Markers 2018, 2018. [CrossRef]

71. Yang, L.L.; Liu, X.Q.; Liu, W.; Cheng, B.; Li, M.T. Comparative analysis of whole saliva proteomes for the screening of biomarkers for oral lichen planus. Inflamm. Res. 2006, 55, 405-407. [CrossRef]

72. Souza, M.M.; Florezi, G.P.; Nico, M.M.S.; de Paula, F.; Paula, F.M.; Lourenço, S.V. Salivary proteomics in lichen planus: A relationship with pathogenesis? Oral Dis. 2018, 24, 784-792. [CrossRef]

73. Camisasca, D.R.; da Rós Gonçalves, L.; Soares, M.R.; Sandim, V.; Nogueira, F.C.S.; Garcia, C.H.S.; Santana, R.; de Oliveira, S.P.; Buexm, L.A.; de Faria, P.A.S.; et al. A proteomic approach to compare saliva from individuals with and without oral leukoplakia. J. Proteom. 2017, 151, 43-52. [CrossRef] [PubMed]

74. Bender, S.D. Burning Mouth Syndrome. Dent. Clin. North Am. 2018, 62, 585-596. [CrossRef]

75. Ji, E.H.; Diep, C.; Liu, T.; Li, H.; Merrill, R.; Messadi, D.; Hu, S. Potential protein biomarkers for burning mouth syndrome discovered by quantitative proteomics. Mol. Pain 2017, 13. [CrossRef] [PubMed]

76. Li, Y.; Wang, D.; Zeng, C.; Liu, Y.; Huang, G.; Mei, Z. Salivary metabolomics profile of patients with recurrent aphthous ulcer as revealed by liquid chromatography-tandem mass spectrometry. J. Int. Med. Res. 2018, 46, 1052-1062. [CrossRef] [PubMed]

77. Amann, A.; de Lacy Costello, B.; Miekisch, W.; Schubert, J.; Buszewski, B.; Pleil, J.; Ratcliffe, N.; Risby, T. The human volatilome: Volatile organic compounds (VOCs) in exhaled breath, skin emanations, urine, feces and saliva. J. Breath Res. 2014, 8, 034001. [CrossRef] [PubMed]

78. Milanowski, M.; Pomastowski, P.; Ligor, T.; Buszewski, B. Saliva-Volatile Biomarkers and Profiles. Crit. Rev. Anal. Chem. 2017, 47, 251-266. [CrossRef]

79. de Lacy Costello, B.; Amann, A.; Al-Kateb, H.; Flynn, C.; Filipiak, W.; Khalid, T.; Osborne, D.; Ratcliffe, N.M. A review of the volatiles from the healthy human body. J. Breath Res. 2014, 8, 014001. [CrossRef]

80. Al-Kateb, H.; de Lacy Costello, B.; Ratcliffe, N. An investigation of volatile organic compounds from the saliva of healthy individuals using headspace-trap/GC-MS. J. Breath Res. 2013, 7, 036004. [CrossRef] 
81. Soini, H.A.; Klouckova, I.; Wiesler, D.; Oberzaucher, E.; Grammer, K.; Dixon, S.J.; Xu, Y.; Brereton, R.G.; Penn, D.J.; Novotny, M.V. Analysis of volatile organic compounds in human saliva by a static sorptive extraction method and gas chromatography-mass spectrometry. J. Chem. Ecol. 2010, 36, 1035-1042. [CrossRef]

82. Malathi, N.; Mythili, S.; Vasanthi, H.R. Salivary diagnostics: A brief review. ISRN Dent. 2014, $2014,158786$. [CrossRef]

83. Torsten, M.; Gomez-Moreno, G.; Aguilar-Salvatierra, A. Drug-related oral malodour (halitosis): A literature review. Eur. Rev. Med. Pharm. Sci. 2017, 21, 4930-4934.

84. Calil, C.M.; Marcondes, F.K. Influence of anxiety on the production of oral volatile sulfur compounds. Life Sci. 2006, 79, 660-664. [CrossRef] [PubMed]

85. Milella, L. The Negative Effects of Volatile Sulphur Compounds. J. Vet. Dent. 2015, 32, 99-102. [CrossRef] [PubMed]

86. Hertel, M.; Hartwig, S.; Schutte, E.; Gillissen, B.; Preissner, R.; Schmidt-Westhausen, A.M.; Paris, S.; Kastner, I.; Preissner, S. Identification of signature volatiles to discriminate Candida albicans, glabrata, krusei and tropicalis using gas chromatography and mass spectrometry. Mycoses 2016, 59, 117-126. [CrossRef]

87. Taware, R.; Taunk, K.; Pereira, J.A.M.; Shirolkar, A.; Soneji, D.; Camara, J.S.; Nagarajaram, H.A.; Rapole, S. Volatilomic insight of head and neck cancer via the effects observed on saliva metabolites. Sci. Rep. 2018, 8, 17725. [CrossRef]

88. Pfaffe, T.; Cooper-White, J.; Beyerlein, P.; Kostner, K.; Punyadeera, C. Diagnostic potential of saliva: Current state and future applications. Clin. Chem. 2011, 57, 675-687. [CrossRef]

89. Pedersen, A.M.L.; Sorensen, C.E.; Proctor, G.B.; Carpenter, G.H.; Ekstrom, J. Salivary secretion in health and disease. J. Oral Rehabil. 2018, 45, 730-746. [CrossRef]

90. Krishnan, K.; Chen, T.; Paster, B.J. A practical guide to the oral microbiome and its relation to health and disease. Oral Dis. 2017, 23, 276-286. [CrossRef]

91. Kakoei, S.; Barkhori, F.; Mirzazadeh, A.; Mohammadi, M.; Gholamhoseinian, A. Influence of menstrual cycle and salivary ß-estradiol on volatile sulfur compound. J. Oral Health Oral Epidemiol. 2012, 1, 5.

92. Boots, A.W.; Smolinska, A.; van Berkel, J.J.; Fijten, R.R.; Stobberingh, E.E.; Boumans, M.L.; Moonen, E.J.; Wouters, E.F.; Dallinga, J.W.; Van Schooten, F.J. Identification of microorganisms based on headspace analysis of volatile organic compounds by gas chromatography-mass spectrometry. J. Breath Res. 2014, 8, 027106. [CrossRef]

93. Hertel, M.; Preissner, R.; Gillissen, B.; Schmidt-Westhausen, A.M.; Paris, S.; Preissner, S. Detection of signature volatiles for cariogenic microorganisms. Eur. J. Clin. Microbiol. Infect. Dis. 2016, 35, 235-244. [CrossRef] [PubMed]

94. Apatzidou, A.D.; Bakirtzoglou, E.; Vouros, I.; Karagiannis, V.; Papa, A.; Konstantinidis, A. Association between oral malodour and periodontal disease-related parameters in the general population. Acta Odontol. Scand. 2013, 71, 189-195. [CrossRef] [PubMed]

95. Cavaco, C.; Pereira, J.A.M.; Taunk, K.; Taware, R.; Rapole, S.; Nagarajaram, H.; Camara, J.S. Screening of salivary volatiles for putative breast cancer discrimination: An exploratory study involving geographically distant populations. Anal. Bioanal. Chem. 2018, 410, 4459-4468. [CrossRef] [PubMed]

96. Cavaco, C.; Perestrelo, R.; Silva, C.; Aveiro, F.; Pereira, J.; Câmara, J. Establishment of the Saliva Volatomic Profile as an Exploratory and Non-Invasive Strategy to Find Potential Breast Cancer Biomarkers; Int. Labmate Ltd.: Hertfordshire, UK, 2014.

97. Porto-Figueira, P.; Pereira, J.A.M.; Camara, J.S. Exploring the potential of needle trap microextraction combined with chromatographic and statistical data to discriminate different types of cancer based on urinary volatomic biosignature. Anal. Chim. Acta 2018, 1023, 53-63. [CrossRef] [PubMed]

98. Silva, C.; Cavaco, C.; Perestrelo, R.; Pereira, J.; Câmara, J.S. Microextraction by packed Sorbent (MEPS) and solid-phase microextraction (SPME) as sample preparation procedures for the metabolomic profiling of urine. Metabolites 2014, 4, 71-97. [CrossRef] [PubMed]

99. Pereira, J.; Silva, C.L.; Perestrelo, R.; Gonçalves, J.; Alves, V.; Câmara, J.S. Re-exploring the high-throughput potential of microextraction techniques, SPME and MEPS, as powerful strategies for medical diagnostic purposes. Innovative approaches, recent applications and future trends Microextraction Techniques. Anal. Bioanal. Chem. 2014, 406, 2101-2122. [CrossRef] 
100. Saigusa, D.; Okamura, Y.; Motoike, I.N.; Katoh, Y.; Kurosawa, Y.; Saijyo, R.; Koshiba, S.; Yasuda, J.; Motohashi, H.; Sugawara, J.; et al. Establishment of Protocols for Global Metabolomics by LC-MS for Biomarker Discovery. PLoS ONE 2016, 11, e0160555. [CrossRef]

101. Biniecka, M.; Caroli, S. Analytical methods for the quantification of volatile aromatic compounds. TRAC-Trends Anal. Chem. 2011, 30, 1756-1770. [CrossRef]

102. Taware, R.; Taunk, K.; Kumar, T.V.S.; Pereira, J.A.M.; Camara, J.S.; Nagarajaram, H.A.; Kundu, G.C.; Rapole, S. Extracellular volatilomic alterations induced by hypoxia in breast cancer cells. Metabolomics 2020, 16, 21. [CrossRef]

103. Taunk, K.; Taware, R.; More, T.H.; Porto-Figueira, P.; Pereira, J.A.M.; Mohapatra, R.; Soneji, D.; Camara, J.S.; Nagarajaram, H.A.; Rapole, S. A non-invasive approach to explore the discriminatory potential of the urinary volatilome of invasive ductal carcinoma of the breast. RSC Adv. 2018, 8, 25040-25050. [CrossRef]

104. Taware, R.; Taunk, K.; Pereira, J.; Dhakne, R.; Kannan, N.; Soneji, D.; Câmara, J.; Nagarajaram, H.; Rapole, S. Investigation of urinary volatomic alterations in head and neck cancer: A non-invasive approach towards diagnosis and prognosis. Metabolomics 2017, 13, 111. [CrossRef]

105. Trefz, P.; Kischkel, S.; Hein, D.; James, E.S.; Schubert, J.K.; Miekisch, W. Needle trap micro-extraction for VOC analysis: Effects of packing materials and desorption parameters. J. Chromatogr. A 2012, 1219, 29-38. [CrossRef] [PubMed]

106. Porto-Figueira, P.; Pereira, J.; Miekisch, W.; Camara, J.S. Exploring the potential of NTME/GC-MS, in the establishment of urinary volatomic profiles. Lung cancer patients as case study. Sci. Rep. 2018, 8, 13113. [CrossRef] [PubMed]

107. Bruheim, I.; Liu, X.; Pawliszyn, J. Thin-film microextraction. Anal. Chem. 2003, 75, 1002-1010. [CrossRef]

108. Shigeyama, H.; Wang, T.; Ichinose, M.; Ansai, T.; Lee, S.W. Identification of volatile metabolites in human saliva from patients with oral squamous cell carcinoma via zeolite-based thin-film microextraction coupled with GC-MS. J. Chromatogr. B: Anal. Technol. Biomed. Life Sci. 2019, 1104, 49-58. [CrossRef]

109. Ide, A.H.; Nogueira, J.M.F. Hollow fiber microextraction: A new hybrid microextraction technique for trace analysis. Anal. Bioanal. Chem. 2018, 410, 2911-2920. [CrossRef]

110. Nogueira, J.M. Novel sorption-based methodologies for static microextraction analysis: A review on SBSE and related techniques. Anal. Chim. Acta 2012, 757, 1-10. [CrossRef]

111. Penn, D.J.; Oberzaucher, E.; Grammer, K.; Fischer, G.; Soini, H.A.; Wiesler, D.; Novotny, M.V.; Dixon, S.J.; $\mathrm{Xu}, \mathrm{Y}$.; Brereton, R.G. Individual and gender fingerprints in human body odour. J. R. Soc. Interface 2007, 4, 331-340. [CrossRef]

112. Kumar, S.; Huang, J.; Abbassi-Ghadi, N.; Španěl, P.; Smith, D.; Hanna, G.B. Selected ion flow tube mass spectrometry analysis of exhaled breath for volatile organic compound profiling of esophago-gastric cancer. Anal. Chem. 2013, 85, 6121-6128. [CrossRef]

113. Sukul, P.; Trefz, P.; Schubert, J.K.; Miekisch, W. Immediate effects of breath holding maneuvers onto composition of exhaled breath. J. Breath Res. 2014, 8. [CrossRef]

114. Yuan, B.; Koss, A.R.; Warneke, C.; Coggon, M.; Sekimoto, K.; De Gouw, J.A. Proton-Transfer-Reaction Mass Spectrometry: Applications in Atmospheric Sciences. Chem. Rev. 2017, 117, 13187-13229. [CrossRef] [PubMed]

115. Zhu, J.; Bean, H.D.; Wargo, M.J.; Leclair, L.W.; Hill, J.E. Detecting bacterial lung infections: In vivo evaluation of in vitro volatile fingerprints. J. Breath Res. 2013, 7. [CrossRef] [PubMed]

116. Sukul, P.; Schubert, J.K.; Oertel, P.; Kamysek, S.; Taunk, K.; Trefz, P.; Miekisch, W. FEV manoeuvre induced changes in breath VOC compositions: An unconventional view on lung function tests. Sci. Rep. 2016, 6, 28029. [CrossRef]

117. Sukul, P.; Schubert, J.K.; Trefz, P.; Miekisch, W. Natural menstrual rhythm and oral contraception diversely affect exhaled breath compositions. Sci. Rep. 2018, 8, 10838. [CrossRef] [PubMed]

118. Trefz, P.; Schmidt, S.C.; Sukul, P.; Schubert, J.K.; Miekisch, W.; Fischer, D.C. Non-Invasive Assessment of Metabolic Adaptation in Paediatric Patients Suffering from Type 1 Diabetes Mellitus. J. Clin. Med. 2019, 8, 1797. [CrossRef] [PubMed]

119. Wilson, A.D.; Baietto, M. Applications and advances in electronic-nose technologies. Sensors 2009, 9, 5099-5148. [CrossRef] [PubMed]

120. Zhang, X.; Lv, Y.; Wang, H.; Tao, X.; Zhang, X. Classification identification of abalone flavoring liquids based on metal sensor array. Carpathian J. Food Sci. Technol. 2016, 8, 107-112. 
121. Wilson, A.D. Diverse applications of electronic-nose technologies in agriculture and forestry. Sensors 2013, 13, 2295-2348. [CrossRef]

122. Brown, J.S.; Prada, P.A.; Curran, A.M.; Furton, K.G. Applicability of emanating volatile organic compounds from various forensic specimens for individual differentiation. Forensic Sci. Int. 2013, 226, 173-182. [CrossRef]

123. Monedeiro, F.; Milanowski, M.; Ratiu, I.A.; Zmyslowski, H.; Ligor, T.; Buszewski, B. VOC Profiles of Saliva in Assessment of Halitosis and Submandibular Abscesses Using HS-SPME-GC/MS Technique. Molecules 2019, 24, 2977. [CrossRef]

124. Ramdzan, A.N.; Mornane, P.J.; McCullough, M.J.; Mazurek, W.; Kolev, S.D. Determination of acetaldehyde in saliva by gas-diffusion flow injection analysis. Anal. Chim. Acta 2013, 786, 70-77. [CrossRef] [PubMed]

125. Alagendran, S.; Archunan, G.; Rameshkumar, K.; Kadalmani, B.; Rodriguez, J.A.; Fernandez, G.; Guzman, R. 2-Nonenal-Ovulatory Specific Volatiles in Human Saliva throughout Menstrual Cycle by Gas Chromatography and Mass Spectrometry Analysis. Am. J. Biochem. Biotechnol. 2010, 6, 187-194. [CrossRef]

126. Bijlsma, S.; Bobeldijk, I.; Verheij, E.R.; Ramaker, R.; Kochhar, S.; Macdonald, I.A.; Van Ommen, B.; Smilde, A.K. Large-scale human metabolomics studies: A strategy for data (pre-) processing and validation. Anal. Chem. 2006, 78, 567-574. [CrossRef] [PubMed]

127. Zhang, A.; Sun, H.; Wang, X. Saliva metabolomics opens door to biomarker discovery, disease diagnosis, and treatment. Appl. Biochem. Biotechnol. 2012, 168, 1718-1727. [CrossRef]

128. Kettaneh, N.; Berglund, A.; Wold, S. PCA and PLS with very large data sets. Comput. Stat. Data Anal. 2005, 48, 69-85. [CrossRef]

129. McGeer, P.L.; Lee, M.; Kennedy, K.; McGeer, E.G. Saliva Diagnosis as a Disease Predictor. J. Clin. Med. 2020, 9, 377. [CrossRef]

130. Rabe, A.; Gesell Salazar, M.; Michalik, S.; Fuchs, S.; Welk, A.; Kocher, T.; Volker, U. Metaproteomics analysis of microbial diversity of human saliva and tongue dorsum in young healthy individuals. J. Oral Microbiol. 2019, 11, 1654786. [CrossRef]

131. Schulz, A.; Lang, R.; Behr, J.; Hertel, S.; Reich, M.; Kummerer, K.; Hannig, M.; Hannig, C.; Hofmann, T. Targeted metabolomics of pellicle and saliva in children with different caries activity. Sci. Rep. 2020, 10, 697. [CrossRef]

132. Tothova, L.; Kamodyova, N.; Cervenka, T.; Celec, P. Salivary markers of oxidative stress in oral diseases. Front. Cell. Infect. Microbiol. 2015, 5, 73. [CrossRef]

133. Nanayakkara, S.; Zhou, X.; Spallek, H. Impact of big data on oral health outcomes. Oral Dis. 2019, 25, 1245-1252. [CrossRef]

134. Malley, J.D.; Dasgupta, A.; Moore, J.H. The limits of p-values for biological data mining. Biodata Min. $2013,6$. [CrossRef]

135. Takeda, I.; Stretch, C.; Barnaby, P.; Bhatnager, K.; Rankin, K.; Fu, H.; Weljie, A.; Jha, N.; Slupsky, C. Understanding the human salivary metabolome. NMR Biomed. 2009, 22, 577-584. [CrossRef] [PubMed]

136. Ballabio, D.; Consonni, V. Classification tools in chemistry. Part 1: Linear models. PLS-DA. Anal. Methods 2013, 5, 3790. [CrossRef]

137. Pereira, J.L.; Duarte, D.; Carneiro, T.J.; Ferreira, S.; Cunha, B.; Soares, D.; Costa, A.L.; Gil, A.M. Saliva NMR metabolomics: Analytical issues in pediatric oral health research. Oral Dis. 2019, 25, 1545-1554. [CrossRef]

138. Casas-Ferreira, A.M.; Nogal-Sánchez, M.d.; Rodríguez-Gonzalo, E.; Moreno-Cordero, B.; Pérez-Pavón, J.L. Determination of leucine and isoleucine/allo-isoleucine by electrospray ionization-tandem mass spectrometry and partial least square regression: Application to saliva samples. Talanta 2020. [CrossRef]

139. Westerhuis, J.A.; Hoefsloot, H.C.J.; Smit, S.; Vis, D.J.; Smilde, A.K.; van Velzen, E.J.J.; van Duijnhoven, J.P.M.; van Dorsten, F.A. Assessment of PLSDA cross validation. Metabolomics 2008, 4, 81-89. [CrossRef]

140. Szymańska, E.; Saccenti, E.; Smilde, A.; Westerhuis, J. Double-check: Validation of diagnostic statistics for PLS-DA models in metabolomics studies. Metabolomics 2012, 8, 3-16. [CrossRef] [PubMed]

141. Al-Shayea, Q.K. Artificial neural networks in medical diagnosis. Int. J. Comput. Sci. Issues 2011, 8, $150-154$.

142. Amato, F.; López, A.; Peña-Méndez, E.M.; Vaňhara, P.; Hampl, A.; Havel, J. Artificial neural networks in medical diagnosis. J. Appl. Biomed. 2013, 11, 47-58. [CrossRef]

143. Mohsen, A.A.; Alsurori, M.; Aldobai, B.; Mohsen, G.A. New Approach to Medical Diagnosis Using Artificial Neural Network and Decision Tree Algorithm: Application to Dental Diseases. Int. J. Inf. Eng. Electron. Bus. 2019, 11, 52-60. [CrossRef] 
144. Nakano, Y.; Takeshita, T.; Kamio, N.; Shiota, S.; Shibata, Y.; Suzuki, N.; Yoneda, M.; Hirofuji, T.; Yamashita, Y. Supervised machine learning-based classification of oral malodor based on the microbiota in saliva samples. Artif. Intell. Med. 2014, 60, 97-101. [CrossRef] [PubMed]

145. Barnes, V.M.; Kennedy, A.D.; Panagakos, F.; Devizio, W.; Trivedi, H.M.; Jonsson, T.; Guo, L.; Cervi, S.; Scannapieco, F.A. Global metabolomic analysis of human saliva and plasma from healthy and diabetic subjects, with and without periodontal disease. PLoS ONE 2014, 9, e105181. [CrossRef] [PubMed]

(c) (1)

(C) 2020 by the authors. Licensee MDPI, Basel, Switzerland. This article is an open access article distributed under the terms and conditions of the Creative Commons Attribution (CC BY) license (http://creativecommons.org/licenses/by/4.0/). 